\title{
JOSE' CARLOS RODRIGUES
}

\section{0 patriarca da imprensa carioca $\left({ }^{*}\right)$}

José Carlos Rodrigues com a sua barba branca e pince-nez de ouro, que usava quando diretor do Jornal do Comércio, lembra-nos uma figura patriarcal. Realmente, durante a sua longa e agitada existência de 79 anos (1844-1923), o período de vinte e cinco em que se colocou a frente do Jornal do Comércio é aquêle em que a sua figura mais se agiganta ante os nossos olhos e em que realmente conquistou o título de patriarca da imprensa.

Atrás da austeridade que o tornava semelhante a um dos profetas bíblicos a que dedicou os seus últimos anos de estudos, escondiam-se o anfitrião gentil e o pai amoroso.

Ao aposentar-se da vida de imprensa, em 1915, lembraramse os jornalistas e os homens públicos do Brasil do seu espírito cavalheiresco ao receber visitantes ilustres entre os quais o ex-presidente Teodoro Roosevelt, de seu espírito de filantropia com que amparava os pobres dando a mão a muitos que ocupam hoje posição eminente na sociedade; da sua profunda simpatia para com os pequenos jornaleiros, chegando até, certa vez, a enviar um dêles a estudar canto na Itália, no que aliás não foi bem sucedido.

Ao tempo da proclamação da República, o já tradicional jornal do Comércio foi vendido a José Carlos Rodrigues e amigos pelo conde de Villeneuve que, num nobre gesto de lealdade, quis acompanhar o imperador no seu auxílio.

Villeneuve, quando tomou a resolução de vender o jornal, quis seguir a tradição de deixá-lo sob a guarda de pessoas da "família", isto é, dos seus redatores. Por isso rejeitava propostas mais vantajosas para cedê-lo a José Carlos Rodrigues que tão brilhantemente havia servido como correspondente no estrangeiro.

Rodrigues manteve o espírito tradicional do Jornal do Comércio: imparcialidade, integridade, inovação. Foi o primeiro na publicação seriada de romances europeus e brasileiros; usando abundantemente notícias de além-mar. Foi ainda pioneiro em adotar a imprensa mecânica, a rotativa, o linotipo e a tomar assinatura

(*). - O presente artigo foi publicado no Jornal do Comércio do Rio de Janeiro em 7 de junho de 1953. A Revista de História, com a gentil autorizaçāo do autor e do Jornal do Comércio resoiveu reproduzi-lo em virtude do interêsse que êle despertou (E. Simóes de Paula). 
a uma agência estrangeira de notícias. Foi o primeiro jornal de tôda a América Latina a tomar como norma a neutralidade polítića.

Já foi dito que José Carlos Rodrigues nasceu para jornalista. Órfão de mãe nos primeiros anos, foi criado por uma tia, proprietária de grande fazenda de café em Cantagalo, Estado do Rio. O pai, também rico fazendeiro de café, mandou-o à capital do país, onde cursou o Colégio Pedro II, e, depois para São Paulo, onde se formou em Direito em 1864, quando contava apenas 20 anos de idade.

Durante o trajeto que, a cavalo, fazia anunalmente de Cantagalo a São Paulo, acontecia-lhe pernoitar na fazenda de amigos que haviam adquirido uma Bíblia de missionários americanos. Entrou, assim, em conhecimento com a Bíblia que passou a ler diàriamente.

Ainda estudante, escrevia artigos para os jornais do Rio e São Paulo. Contava apenas 19 anos de idade quando publicou uma edição anotada da constituição imperial, que foi reeditada dez vêzes. Com outro estudante, que mais tarde iria ajudá-lo na aquisição do Jornal de Comércio, fundou uma revista jurídica, cuja publicação continuou regularmente por 6 anos.

Logo que terminou o curso, em 1864, veio para o Rio e iniciou-se no exercício da advocacia. Quando um ex-professor seu foi escolhido ministro do Estado, êste o convidou para secretário. Aparecia-lhe ante os olhos uma carreira brilhante, carreira que os inimigos políticos the cortaram, aproveitando-se de um ato imprudente que cometera. José Carlos Rodrigues abandonou tudo e exilou-se do país, vivendo entre americanos e inglêses vinte anos, até que a morte da tia rica fê-lo voltar ao Brasil, para entrar na posse de uma herança.

Herdeiros únicos, êle e uma irmã de nome Carlota Rodrigues Lopes, dos haveres deixados pela tia, deram imediatamente liberdade aos últimos escravos na fazenda de café em Cantagalo. Rodrigues que cerrava fileira ao lado dos abolicionistas, foi sempre amigo de Joaquim Nabuco com quem manteve estreitas relações em Nova York e Londres.

No início da sua vida pública no Rio em 1864, Rodrigues estudava inglês com George Whithill Chamberlain, estudante universitário americano que para aqui viera em 1861, em busca de saúde e aqui ficara retido, sem meios de regressar á Pátria, porquanto os navios americanos participavam da destruição da terrível Guerra Civil durante quatro anos. Terminada a Guerra em 1865, regressou aos Estados Unidos, completou o seu curso teológico e veio para o Brasil na qualidade de missionário da Igreja Presbiteriana. Foi ainda Chamberlain que em 1870 fundou em São Paulo um pequeno colégio americano que vem crescendo através dos anos, até tornar-se hoje a florescente Universidade Ma- 
ckenzie, que conta 4.800 estudantes. Tem ela um edifício "José Carlos Rodrigues".

Foi Chamberlain quem influenciou o espírito de José Carlos Rodrigues quanto ao estudo da Bíblia e do protestatismo.

Já durante a viagem para Nova York, Rodrigues traduziu para o português um folheto evangélico. Ao desembarcar, pôs-se logo em contato com Chamberlain e a American Tract Society que divulgava tais folhetos e ali obteve o seu primeiro emprêgo. Jamais perdeu o contato com os protestantes americanos $\mathrm{e}$ até 1882, quando deixou Nova York, já havia escrito em português oito livros didáticos para a escola americana que seu amigo Chamberlain fundara em São Paulo.

Ocupou-se também em traduzir para o português o almanaque do Dr. Ayer que se destinava a propaganda dos produtos medicinais no Brasil. Enamorou-se de uma loira filha do Dr. Ayer, e êste aborreceu-se pois não gcstaria de ver a filha casar-se com um brasileiro desconhecido.

Em Washington passou vários meses ocupado na tradução de documentos para uso do juiz brasileiro nomeado árbitro na Suiça da questão do cruzador confederado "Alabama" que destruiu tantos navios da União. Residia em casa do eminente ministro da Justiça, Caleb Cushing, que the oferecou o lugar de səcretário da delegação americana de àrbitragem em Genebra caso decidisse êle a naturalizar-se americano, o que recusou porque nele era muito intenso o sentimento de brasilidade.

Foi nessa ocasião nomeado correspondente do Diário Oficial do Brasil, e também do Jornal do Comércio, atividade que exerceu até 1890 , quando adquiriu e passou a dirigir êste tradicional órgão da imprensa.

Fundou em 1870 o Novo Mundo, para circular no Brasil, revista que continuou a sair regularmente durante nove anos, chegando a ter uma tiragem de oito mil exemplares, o que era mui significativo naquele tempo. Além de noticias de interêsse geral para os brasileiros, Rodrigues escrevia sôbre ciência, comércio, invenções, religião, literatura e o progresso geral na América do Norte. Revelou espírito "ianque" quando distribuiu ações da sua revista ao seu tipógrafo, ao gravador e ao comerciante que the vendia papel.

Ainda, com admirável espírito prático do americano, além de arranjar anúncios do Dr. Ayer, obteve auxílio de rico comerciante de Nova York que importava borracha do Amazonas, o que the permitiu melhorar a sua revista. Muitos dos artigos de crítica literária e sôbre assuntos latino-americanos, uma vez publicado em Novo Mundo, êle os traduzia para The Nation, revista liberal de Nova York.

Espírito dinâmico, êle fazia tudo sòzinho e para que a revista tivesse a máxima regularidade na sua distribuição, acompanhava 
em pessoa o transporte delas até o navio que mensalmente largava para o Rio.

Observando certa vez em 1870 que o navio recebia três lindos bondes destinados ao Rio, procurou logo o fabricante, John Stephenson, e conseguiu dêle um anúncio remunerado. Por meio de seus artigos, Rodrigues pregava aos brásileiros os ideais alevantados de sadio nacionalismo, despertando a sêde do progresso e a adoção de tudo o que fôsse útil para o Brasil. Esta foi também a sua diretriz como proprietário do Jornal do Comércio.

Com saudade da Pátria, comprazia-se em discorrer sôbre as grandezas do Brasil: as riquezas minerais, a majestade das suas cachoeiras, maiores que Niagara, a imponência da Amazônia, etc. Com legítimo orgulho fazia menção das atividades dos brasileiros nos Estados Unidos, e prestou valioso auxílio a muitos patrícios. Agentes do Novo Mundo no Brasil freqüentemente recebiam àssinatura do New York Times, que alugara a Rodrigues várias dependências do seu antigo edifício próximo da Prefeitura.

Quando o Prof. C. F. Hartt da Cornell University chefiou uma expedição científica na Amazônia, batizou um fóssil ali descoberto com o nome de Rodrigues, como sinal de gratidão pela ajuda e incentivo que êste lhe prestara.

Com o seu grande espírito de patriota que desejava ver a sua pátria conhecida no mundo, Rodrigues financiou em parte os primeiros anos da longa carreira no Brasil do famoso geólogo, J. C. Branner, que se fêz autor da primeira gramática da língua portuguêsa publicada nos Estados Unidos e de muitas obras sôbre geologia do Brasil, tornanda-se mais tarde reitor da Stanford University.

Nesta posição, o Dr. Branner criou o interêsse pelos estudos brasileiros que até hoje continuam đirigidos pelo notável brasilianista Prof. Ronald Hilton, redator do Who's Who in Brazil, do mensário Hispanic Americán Report, e que também traduziu para o inglês a vida de Joaquim Nabuco de autcria de D. Carolina Nabuco.

Em Stanford o autor destas linhas teve ocasião de estudar em 1931 com o grande sociólogo Prof. Gilberto Freyre, que ali fôra lecionar a convite do saudoso Prof. Percy Alvin Martin, notável historiador.

Exaltando o valor da leitura da Bíblia Sagrada, bem ccmo a importância das escolas públicas como alicerce do progresso do povo norțe-americano, José Carlos Rodrigues veio a merecer calorosos elogios do Rev. Dr. J. C. Fletcher, co-autor do melhor livro escrito por americanos sôbre o Brasil no século passado.

D. Pedro II, com justiça cognominado o magnânimo, tinha conhecimento dos grandes serviços que Rodrigues estava prestando ao Brasil, não só no mundo das ciências como também através das magníficas edições do Novo Mundo. Sabia da sua prestimosa 
colaboração para as exibições brasileiras na Exposição de Filadélfia de 1876 , bem como da sua atuação para a brilhante rec£pção que em Nova York the promoveu a American Geographical Society da qual Rodrigues era membro. Querendo pois passar uma esponja e apagar de vez a mancha que uma leviandade de moço the deixara no nome quando funcionário do Ministério da Justiça em 1868, no Rio, o imperador subiu um dia as escadarias do edifício do New York Times para agradecer a Rodrigues os serviços prestados ao Brasil. Conferiu-lhe assim honra inédita e recomendou-lhe ainda, na qualidade de correspondente do Jornal do Comércio, que não deixasse de mencionar o fato, o que realmente fêz, mas mui modestamente em poucas linhas.

Rodrigues era amante da música e chegou a editar em Nova 'York a Musical Review. Quis mostrar a sua gratidão ao imperadcr, saudando-o com uma orquestra quando partia o navio que o conduzia à Europa .

Ainda em Nova York, fundou em 1878, com a colaboração do famoso engenheiro e abolicionista André Rebouças, a Revista Industrial, publicação que teve de cessar como a do Novo Mundo quando em dezembro de 1879 interrompeu-se a linha de paquetes para o Rio de Janeiro.

Quando em 1880 o famoso de Lesseps, o herói do Canal de Suez, empreendeu a construção do Canal do Panamá, o New York Wcrid nomeou Rodrigues como seu correspondente especial. A inépcia e a malária fizeram qùe a arrojada emprêsa culminasse num ruidoso desastre.

Como resultado dos seus artigos, assás discutidos, publicados em 1880 sôbre o Panamá, foi convidado pelo presidente Hayes a visitar a Casa Branca e explicar a situação a altos funcionários americanos.

Rodrigues publicou em Nova York e Londres em 1885 um livro em que profèticamente declarava caber sòmente ao povo americano a tarefa de construir o Canal do Panamá.

Destarte, quando em 1913 Teodoro Roosevelt estava no Rio, de passagem para Mato Grosso, foi hóspede de José Carlos Rodriques. Declarou o explorador que ao abrir o Canal do Panamá estava apenas cumprindo a profecia de um brasileiro.

Como membro do Clube Universitário de Nova York, Rodrigues manteve relações com os ex-presidente Grant e Garfield, e também com Teodoro Roosevelt e Elihu Root, futuro ministro do Exterior.

Quando em 1882 aceitou o convite para seguir para Londres e representar os interêsses brasileiros em negociações financeiras (incluindo um empréstimo que não se concretizou para a estrada de ferro de Cantagalo), Rodrigues era ainda pobre. Adquirira, porém, muita experiência e excelentes amigos. Era um jornalista completo, homem de energia e fôrça de caráter. De Londres con- 
tinuava a escrever para o Jornal do Comércio, notadamente sôbre assuntos, norte-americanos. Contribuia também para os methores jornais britânicos, entre os quais The Times, que êle tomou como modêlo logo que assumiu a direção do Jornal do Comércio.

Depois que regressou ao Brasil em 1887 e recebeu rica herança, sentiu-se abastado e pensou em constituir família. Casou-se em Londres com a srta. Jane Sampson. Ali the nasceram duas filhas. Devido ao seu estado de saúde, Mme. Rodrigues fixara residência em Londres e fazia contínuas viagens ao continente, esfecialmente a París, onde passou muitos anos.

A filha mais velha, de nome Janet, casou-se com um inglês inteligente e culto, muito ligado ao Brasil, secretário que foi em París do engenheiro e empreendedor milionário americano, Percival Farquhar, fundador de trinta emprêsas no Brasil que era amigo de Rodrigues. O marido de Janet, Sir William Garthwaite, torncu-se magnata da navegação e foi elevado à nobreza pelo rei da Inglaterra. Janet é já falecida, deixando filhos e netos na Inglaterra.

A segunda filha, D. Evelina Rodrigues Hawes, reside agora no Rio, depois de haver cuidado em Londres durante os anos difíceis da guerra da sua velha progenitora enferma e que veio a falecer em 1944.

Algumas cartas de Rodrigues se queimaram num princípio de incêndio de sua antiga residência em Londres. Mas D. Evelina possui ainda ali uma parte da correspondência de seu pai, com Rio Branco, Nabuco, Rui, Campos Sales e outras grandes figuras do seu tempo.

D. Evelina pretende êste ano visitar a Inglaterra bem como cs seus parentes, vinte descendentes de Rodrigues que ali residem. Atendendo às sugestões de vários membros da Academia Brasileira de Letras e do Instituto Brasileiro de História e Geografia (incluindo o Dr. Elmano Cardim, autor de um excelente ensaio sôbre Rodrigues), ela deverá trazer para o Rio a preciosa correspondência e os diários de seu pai. Devem constituir preciosa fonte de informações não só para melhor conhecimento dos acontecimentos mais importantes da História da República até 1915, como também para a biografia de Rodrigues que o autor dêste artigo está preparando.

Começou Rodrigues em Londres a formar a sua magnífica coleção de livros raros e mapas sôbre o Brasil, comprando-os também em París e outras cidades da Europa. Manteve contacto com Rio Branco, Nabuco e Oliveira Lima. Êste acabou legando a sua. rica brasiliana à Universidade Católica de Washington; onde o bibliotecário é o Professor de História do Brasil, Dr. Manoel Cardozo, formado pela Universidade de Stanford, que planejava es-: crever uma biografia de Oliveira Lima. 
Tendo desempenhado uma segunda missão financeira para o seu govêrno, no ano de 1890 , Rodrigues voltou ao Rio e, com o auxílio de amigos, adquiriu o Jornal do Comércio.

Durante aquêles dias agitados dos primeiros anos da República, anos de censura da imprensa e ditadura militar, dirigiu como estadista o jornal mais influente do Brasil. Aos políticos ainda inexperientes do novo regime sugeriu decisóes democráticas e respeito à nova constituição, obra quase exclusiva de seu amigo Rui Barbosa, que quando ministro da Fazenda the oferecera o cargo de delegado do Tesouro em Londres.

Corajosamente se opôs ao autoritarismo militar chefiado por Floriano (1893-94) do que resultou a revolta naval e quase em guerra civil no extremo sul do país. Em plena Guanabara as fortalezas estavam em duelos freqüentes com as belonaves revoltadas.

Rodrigues refugiou-se na residência de um amigo íntimo, o arquiteto e construtor do atual edifício do Jornal do Comércio, Antonio Jannuzzi, e ali dedicou-se mais ao estudo da Bíblia e escreveu a vida de Cristo. Finalmente, disfarçado em marinheiro inglês conseguiu chegar a bordo de um vapor inglês que o transportou para Londres, onde passou algum tempo ao lado da família.

Também Rui buscou o exílio em Londres, de onde fêz publicar no Jornal do Comércio as famosas "Cartas da Inglaterra".

Normalizada a situação em novembro de 1894 , com a posse de Prudente de Morais, Rodrigues voltou à direção do seu jornal no Rio.

Ao presidente Campos Sales foi especialmente útil em missões financeiras em Londres. A pedido do eminente ministro da Fazenda, Joaquim Murtinho, obteve um empréstimo na Inglaterra para aliviar as onerosas garantias de juros que pesavam sôbre as estradas de ferro. Chegou a escrever um livro a êste respeito. Com uma única exceção, por todos êstes grandes serviços prestados ao Brasil, Rodrigues não aceitou nenhuma remuneração. Geralmente desempenhava tais comissões quando fazia a sua viagem anual a Londres e París com o fim de encontrar-se com a família .

Desde 1890 até a sua morte, ocorrida em 1923, José Carlos Rodrigues foi amigo íntimo do Rev. Dr. H. C. Tucker, mui conhecido pastor protestante americano que aqui viveu mais de sessenta anos (1886-1947) e que atualmente, com 95 anos de idade, reside com sua filha em Pensilvânia. Entre os americanos amigos do Brasil, o Rev. Tucker é o mais velho. Sob o título God's Good Neighbor (O Bom Vizinho de Deus), o Reader's Digest publicou sôbre êle, em setembro de 1943, excelente artigo.

Quando secretário da Sociedąde Bíblica Americana no Rio, recebia freqüentemente o Dr. Tucker conselhos e auxílio de Rodrigues, que por sua vez costumava comprar Bíblias e Novos Tes- 
tamentos para distribuir aos amigos. Um e outro queriam que a Bíblia se tornasse conhecida de milhões de famílias brasileiras.

Foi em Nova York que Rodrigues veio a conhecer os diretcres da Scciedade Bíblica. Em 1882 estava empenhado na tradução do Novo Testamento para o português, quando teve de partir para Londres e interromper o seu trabalho. Regressando ao Brasil, aqui prestou grande auxílio à comissão de pastores encarregada de fazer nova tradução da Bíblia.

Dcis admiradores de José Carlos Rodrigues renderam-lhe justa homenagem: o Rev. Tucker, num opúsculo de 40 páginas em inglês, editado em 1925, pela Sociedade Bíblica em Nova York; e o Prof. Luciano Lopes, numa conferência na Academia Carioca de Letras, publicada depois pela Academia e no Jornal do Comércio.

Muito imparcialmente, o Jornal do Comércio publicava as notícias religiosas mais interessantes tanto de católicos como de protestantes nos anos em que Rodrigues era o seu dono. Defensor incansável da liberdade religiosa, Rodrigues criticava acerbamente tôdas as manifestações de fanatismo no interior do Brasil, tais como as perseguições aos evangélicos, a destruição dos seus templos e a queıma de suas Bíblias como por vêzes faziam sacerdotes intolerantes.

Sem lucro algum, fazia imprimir na sua tipografia livros evangélicos. Enquanto viveu foi o maior amigo que tiveram os protestantes no Brasil. Ainda em 1900, participando das comemorações do quarto centenário do descobrimento, escreveu um livro sob o título "Religiões acatólicas do Brasil".

Muitos líderes prctestantes quando no Rio visitavam os seus escritórios ou eram convidados para um jantar em sua casa hospitaleira.

Ajudou o Dr. Tucker na fundação do centro pioneiro do bem estar social nas favelas do Rio de Janeiro, em 1906, o Instituto Central do Povo, que continua a prestar excelentes serviços aos pobres.

Esta benemérita instituição que é a Associação Cristã de Moços (A.C.M.) no Rio deve muito a José Carlos Rodrigues, que participou da sua fundação em 1893 com o diretor, Myron Clark. Rodrigues adquiriu para a A. C. M. o esplêndido lote na Esplanada do Castelo e chefiou a campanha para a sede que esta ocupou durante 25 anos. Em reconhecimento, a A. C. M. deu o nome de J. C. Rodrigues à sua biblioteca.

De 1887 a 1902 esteve em relações íntimas com o único jornalista americano radicado no Rio, Andrew J. Lamoureux, que publicou um guia do Rio de Janeiro e editava um jornal, The Rio News. Lamoureux e o Rev. Tucker eram os seus fundadores, com a colônia inglêsa no Rio em 1893, numa época em que a febre amarela matou muitos forasteiros do Hospital dos Estran- 
geiros, que acabava de construir uma ala nova. Tornara-se Lamoureux amigo de D. Pedro II, a quem conhecera na Exposição de Filadélfia em 1876 e foi a convite do imperador que veio ao Brasil.

Lamoureux, sempre inimigo da escravidão, ligou-se aos abolicionistas.

Tcrnaram-se famcsos no Jornal do Comércio os artigos emineintes apologéticos que Rodrigues escreveu especialmkinte por ocasião do Natal e da Semana Santa sôbre a vida e ensinamentos de Cristo.

Quando esteve no Rio, em 1910, William Jennings Bryan, que por quatro vêzes foi candidato do Partido Democrático à presidência dos Estados Unidos, foi hóspede de Rodrigues. Bryan proferiu na A. C. M. e também no Palácio Monroe a sua célebre conferência, "O Príncipe da Paz". Nela declarou, na presença de Rio Branco e centenas de brasileiros eminentes, que os Estados Unidos deveriam exportar mais Bíblias e menos munições e que uma boa parte da riqueza americana deveria de preferência ser usada para estabelecer na América Latina instituições educativas da natureza do Mackenzie de São Paulo. A tôdas estas declarações o Jornal do Comércio deu lugar de especial relêvo.

Por sua vez, na revista que publicava na outra América, Bryan fazia justiça à personalidade de José Carlos Rodrigues, declarando que êste era um dêsses raros espíritos que de vez em quando aparecem e deixam permanente impressão na alma de sua geração e de sell país. Observou ainda que Rodrigues, durante os quinze anos que esteve nos Estados Unidos, largamente se inspirava do espírito da demccracia, chegando até a aconselhar o imperador a imitar George Washington, isto é, a proclamar a República e eleger-se seu primeiro presidente e Pai da Pátria. Em Rcdrigues exaltou Bryan o homem de largas visões, o campeão dos grandes ideais, o homem de consciência, coragem e pureza de vida, o homem que, recusando embora uma pasta de Ministro e uma cadeira no Senado, exercia todavia, mais do que qualquer outro uma grande influência no Brasil.

E' curioso que Rodrigues foi dos últimos a adquirir terrenos na Avenida Rio Branco, näo obstante haver apciado o prefeito Fereira Passos no seu programa de remodelação da Capital da República com a abertura em 1904-1905 de uma avenida central. Foi só em 1906 que, ainda a custo, se decidiu a adquirir um lote na esquina da rua do Ouvidor com a avenida. Contratou com Jannuzzi e um arquiteto francês a construção do edifício maciço e semi-clássico, com sete andares que em 1908 foi inaugurado com um grande salão de concertos e conferências no último andar. Ali instalou o que então havia de mais moderno para um jornal.

Rodrigues fêz virtualmente do Jornal do Comércio o portavcz do Itamarati e do seu grande Ministro Rio Branco. Isto para 
o progresso do Brasil e seu maior prestígio entre as nações. Era mui freqüente que Rio Branco, terminados os trabalhos do dia, viesse passar horas na redação do Jornal do Comércio para um prolongado "bate-papo" com o seu grande amigo. Tornou-se-lhe isto uma espécie de hábito. Deu motivo a que jornalistas estrangeiros visitando o Rio, escrevessem que o Jornal do Comércio era um órgão semi-oficial.

Rodrigues muito fêz para incrementar as boas relações de amizade entre o Brasil, os Estados Unidos e Inglaterra. Quando a imprensa sensacional explorava um incidente prejudicial às boas relações de amizade com estas nações, bastava que o embaixador enviasse a Rodrigues uma exposição exata dos fatos e logo um artigo no Jornal do Comércío esslarecia o assunto e liquidava o incidente.

Exemplo desta sua atuação feliz encontra-se no que aconteceu depois da grande Conferência Pan-Americana de 1906, presidida por Rio Branco, Nabuco e Elihu Root. Circulou a notícia de que ao desembarcar em Nova York deu-se um incidente com Nabuco, embaixador em Washington, tendo sido êste insultado pelas autcridades americanas de imigração. Os jornais sensacionalistas exploravam o caso. Então o embaixador americano, Lloyd Griscam, ainda vivo, obteve de Nabuco por cabograma os fatos, negando inteiramente qualquer incidente ofensivo. Griscom enviou o cabograma a Rodrigues e no dia seguinte o Jornal do Comércio, num artigo bem lançado, esclareceu o assunto e o liquidou de vez.

Fato semelhante aconteceu quando Bryan era Ministro das Relações Exteriores no govêrno de Wilson, a quem Rodrigues tributava real admiração, considerando-o estadista mundial, chegando mesmo a traduzir alguns de seus famosos discursos e a publicá-los em livro. Ora, houve enorme grita de vários jornais cariocas contra o "imperialismo ianque" quando os Estados Unidos em 1913-1914 tentaram intervir na guerra civil do México, onde mithares de americanos perderam as suas propriedades e muitos a própria vida. Então o embaixador americano, Edwin Morgan, enviou a Rodrigues um longo relatório sôbre a trágica situação do México. Logo que Rodrigues, pessoalmente traduziu o, relatório e publicou-o no Jornal do Comércio, acalmou-se a campanha.

Percival Farquhar, que foi um dos fundadores da Light em 1905 no Rio, bem como construtor die portos e estradas de ferro antes de tomar conta da Itabira, descobriu êste espírito de boa vcntade em Rodrigues. Quando em 1906-1907 começou a construção do pôrto de Belém do Pará, destinado a facilitar mais rápido escoamento do então produto número dois do Brasil, que era a borracha, um chantagista europeu tentou arruinar-lhe a emprêsa porque Farquhar, que encarnava a proverbial honestidade dos Quakers de Pensilvânia, lhe recusara as propostas indecorosas. Então, através da seção de "Publicações a pedido" do Jornal do 
Comércio, o chantagista começou uma campanha de difamação contra uma emprêsa inegàvelmente necessária ao desenvolvimento econômico do Brasil. Procurou Rodrigues ouvir de Farquhar uma exata exposição dos fatos e isto para que o Jornal do Comércio p£la primeira vez negasse o uso irrestrito daquela seção de "Publicaçōes a pedido", reduzindo a silêncio o chantagista, logo depois, por meio de uma de suas "várias". Farquhar pôde assim completar o pôrto de Belém, a Estrada de Ferro Madeira-Mamoré, bem como outras obras de importância. Tornou-se amigo de Rodrigues, cuja casa em París passou a frequentar durante vários anos.

Espírito humanitário, Rodrigues tomou sempre vivo interêsse pela Santa Casa de Misericórdia. Quando tomou parte na diretoria na qualidade de mordomo, dotou-a com um Hidroterapium, modernizou grande parte das suas antiquadas instalações — ajudando com seus próprios recursos a comprar equipamentos novos para quatro salas de operaçōes.

Ao produto da venda da sua rica biblioteca brasiliana, juntou dinheiro de outras fontes e empregou tudo na construçáo de um hospital de crianças na rua Miguel Frias, no Mangue.

A biblioteca de José Carlos Rodrigues, cujo catálogo êle próprio organizara, chegando a publicar o primeiro volume (o Ministério de Educação pretende em breve publicar o outro volume), está enriquecendo hoje o patrimônio da Biblioteca Nacional, doada pelo Ur. Julio B. Cttoni, que a adquirira.

Muitas condecoraçōes recebeu Rodrigues de governos estrangeiros, entre os quais do imperador do Japão, grato ao Jornal do Comércio pelo modo por que acompannara a marcha clos acontecimentos na guerra russo-japonesa.

Quando em 1909 visitou novamente Nova York, quiseram dois diplomatas américanos que conheceram Rodrigues há décadas, oferecer-lhe um banquete para o qual foram convidados não só o embaixador Joaquim Nabuco, mas também muitos daqueles jornalistas que conheceram Rodrigues naquele período de 1867 a 1882 e eram agora redatores de jornais importantes em Nova York. Observou Nabuco que o homenageado, ante a grande honra recebida, não demonstrou nenhuma emoção. O seu espírito a êste respeito era profundamente sạônico: não deixava nunca transparecer as emoções que experimentava no íntimo, como mais tarde veio a confessar em 1913 no Banquete de despedida do Jornal do Comércio.

À medida que passavam os anos, sentia-se cada vez mais inclinado para o estudo do livro que maior influência exercera na sua vida: a Bíblia Sagrada. Era plano seu, ao deixar as lides jornalísticas, consagrar o resto dos seus anos a escrever um estudo completo da Bíblia com o intuito de difundir os seus ensinamentos mais amplamente no Brasil. 
Com o fim de adquirir livros especializados sôbre o assunto, visitou Nova York pela última vez em 1915 e aproveitou a ocasiäo para promover ali a estréia da jovem pianista brasileira Guiomar Novais, que começava a refulgir no mundo da música.

Foi um di.jlomata, um verdadeiro estadista, êste patriarca da imprensa brasileira que veio a falecer em París $\in m$ 1923. Felcs grancies serviços que prestou ao Brasil é justo que o seu nome não permaneça deslembrado, mas seja perpetuado nalguma praça pública, nalguma rua ou escola desta cidade.

CHARLES ANDERSON GAULD 